\title{
Microscopic Investigation of the Morphology of Various Photocatalytic Active Nanostructures
}

\author{
Nataliya Murafa ${ }^{*}$, Václav Steng1*, Jan Šubrt, Snejana Bakardjieva*, Vendula Houšková* \\ *Institute of Inorganic Chemistry of the ASCR, v. v. i., 25068 Řež, Czech Republic
}

It is well known that properties of inorganic materials are directly dependent on their structure and morphology. Chemical compounds of the same composition but different morphology can show out profoundly different properties. For example, titania dioxide of anatase modification. With common precipitation processes are obtained quite big particles of titania dioxide in anatase modification applicable as a special pigments or fillers. During the homogeneous hydrolysis are obtained titania dioxides (anatase modification) of well crystalline nanoparticles with a big specific surface area. These materials show out photocatalytic properties. Its illumination with UV light leads to rapid decomposition of toxic chemicals and organic materials. This is only one of the reasons why scientists at length investigate new structural and morphological properties of common chemical adducts.

Homogeneous hydrolysis with urea and thioacetamide [1, 2] are reported in this work. The decomposition of urea $\left(\mathrm{CH}_{4} \mathrm{~N}_{2} \mathrm{O}\right)$ in aqueous solution is accompanied by slow and controlled supply of ammonia $\left(\mathrm{NH}_{3}\right)$ and carbon dioxide $\left(\mathrm{CO}_{2}\right)$ into the solution. The smooth $\mathrm{pH}$ increase obtained by the degradation of urea with the concerted release of $\mathrm{OH}^{-}$and $\mathrm{CO}_{3}{ }^{2-}$ ions, usually leads to the precipitation of metal hydrous oxide particles of controlled particle morphology [3]. All microstructural parameters such as particle's shape and size, specific surface area and porosity are quite sensitive towards $\mathrm{pH}$, metal ion concentration, temperature and ageing time. In the same way as the urea method, homogeneous precipitation of metal sulphides by thermal decomposition of thioacetamide (TAA) is also a viable method to prepare metal oxide nanoparticles [4]. Thioacetamide releases hydrogen sulphide at a temperature higher than $60{ }^{\circ} \mathrm{C}$ in acidic solution. The reaction products are nanosized spherical particles with a well-developed microstructure, but different from homogeneous precipitation with urea. Such materials can be produced with a high specific surface area [5].

The prepared samples obtained by the homogeneous hydrolysis in the aqueous solution with urea and thioacetamide as precipitating agents were characterized by several instrumental techniques EDX (Energy Dispersive X-ray), XRD (X-ray Powder Diffraction), BET (Surface Area), BJH (Porosity), SEM (Scanning Electron Microscopy), TEM (Transmission Electron Microscopy), and HRTEM (High Resolution Transmission Electron Microscopy).

In this research, various morphologically interesting particles (see Fig. 1-6) of mixed sulfides and hydroxyl-oxides of $\mathrm{Zn}$ and $\mathrm{Cd}$, Ti and $\mathrm{Zn}$ and $\mathrm{Ti}$ (anatase modification) were by homogeneous hydrolysis with urea and thioacetamide synthesized and tested. All foregoing material properties of specimens obtained by both of synthesized methods were monitoring, particularly photocatalytic activity. 


\section{References:}

[1] V. Štengl et al., Micropor. Mesopor. Mater. 110 (2-3) (2008) 370-378.

[2] V. Houšková et al., J. Phys. Chem. Solids 69 (7) (2008) 1623-1631.

[3] V. Štengl. et al., Solid State Phenomena 90-91 (2003) 121-126.

[4] T. Nomura et al., J. Colloid Interface Sci. 223 (2000) 179.

[5] V. Hošková et al., J. Phys. Chem. A 111 (2007) 4215.

[6] This work was supported by the Ministry of Education, Youth and Sports of the Czech Republic (project № LC 0523) and by the Academy of Sciences of the Czech Republic (Project № AV0Z40320502)

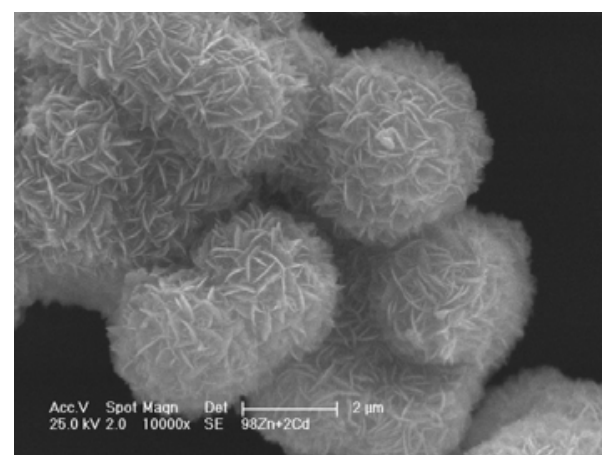

Fig.1 SEM micrograph of mixed sulphides $\mathrm{Cd}$ and $\mathrm{Zn}$ precipitated with thioacetamide

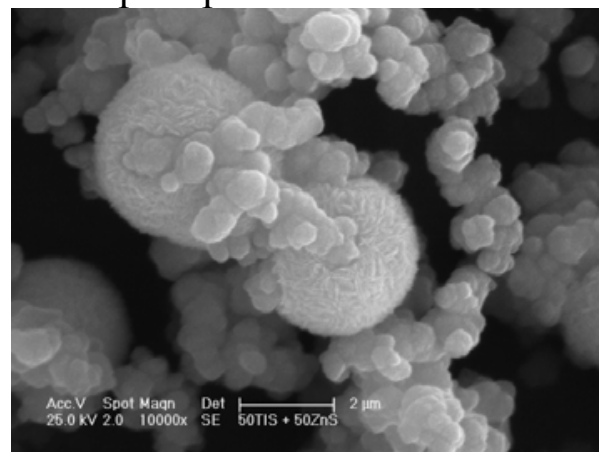

Fig.3 SEM micrograph of mixed sulphides $\mathrm{TiO}_{2}-\mathrm{ZnS}$ precipitated with thioacetamide

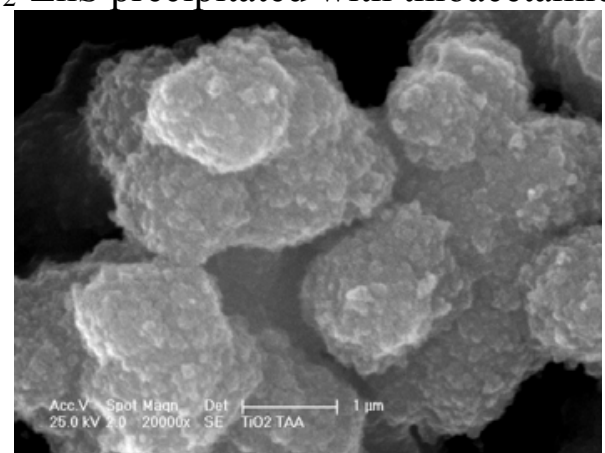

Fig.5 SEM micrograph of $\mathrm{TiO}_{2}$ precipitated with thioacetamide

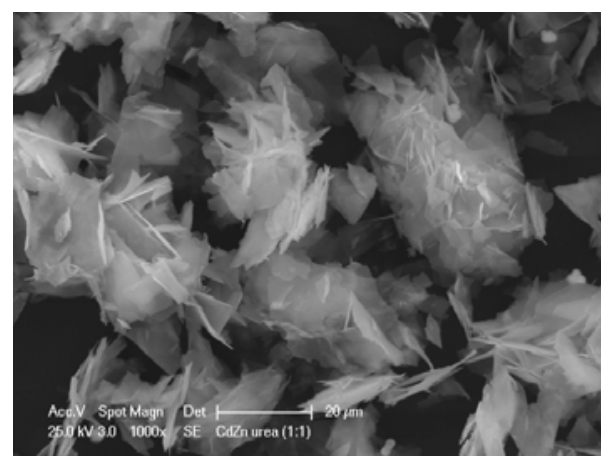

Fig.2 SEM micrograph of mixed hydroxyoxides $\mathrm{Zn}-\mathrm{Cd}$ precipitaded with urea

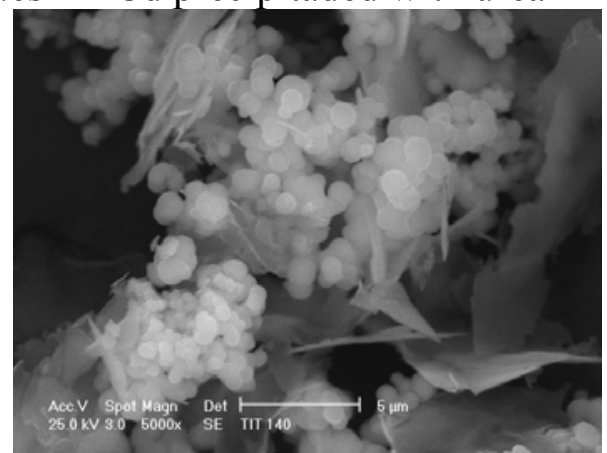

Fig.4 SEM micrograph of mixed hydroxyoxides Ti-Zn precipitaded with urea

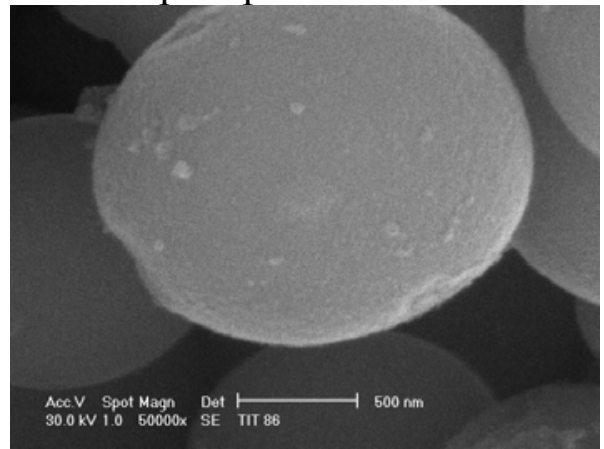

Fig.6 SEM micrograph of of $\mathrm{TiO}_{2}$ precipitated with urea 